\title{
Predictors of Educational Outcomes of Students with Multiple Disabilities: Results from a National Study
}

\author{
Kymberly Bowlen, Kristen Osiniak, Tyler Syms, Karen H. Larwin \\ Department of School Psychology, Youngstown State University, United States of America
}

\begin{tabular}{l}
\hline \hline Article Info \\
\hline Article history: \\
Received Jun 26, 2018 \\
Revised Jul 13, 2018 \\
Accepted Aug 26, 2018 \\
\hline Keyword: \\
Educational Experience \\
Life Beyond Formal Schooling \\
Relationship Between Children \\
with Multiple Disabilities \\
Transition And Vocational \\
Programs \\
\end{tabular}

\begin{abstract}
Parents, siblings, and peers have an immeasurable effect on shaping children into who they become as individuals. Many factors, such as one's relationships with these individuals, may have lasting effects on the educational and vocational outcomes of children who have multiple disabilities. The purpose of the present study is to investigate the relationships of children with multiple disabilities, as well as their perceptions regarding their educational experiences to determine the effects these factors may have on their future outcomes. The goal of the present study is to determine how potential correlations may influence children with multiple disabilities during transition and vocational programs, as well as their outcomes in life beyond formal schooling.
\end{abstract}

Copyright (C) 2018 Institute of Advanced Engineering and Science. All rights reserved.

\section{Corresponding Author:}

Karen H. Larwin, Department of School Psychology, Youngstown State University, United States of America Email; khlarwin@ysu.edu

\section{INTRODUCTION}

Though there may be difficulties associated with raising a child with multiple disabilities, research has indicated that the siblings of these individuals commonly have positive relationship with them [1]. Specifically, siblings of children with multiple disabilities were found to be more helpful and maternal toward their sibling when compared to their relationships with typically developing siblings [1]. Research has indicated that positive sibling relationships positively impact the development of children and that these relationships foster appropriate identity development [2]. Role-reversal is sometimes found in such sibling relationships, wherein the younger, typically developing sibling assumes the role of the older sibling when interacting with the child that has multiple disabilities [2]. Despite concerns related to role-reversal, children with the multiple disabilities still feels loved and cared for by their younger, typically developing sibling [2]. Additionally, positive peer relationships provide social supports to children as well, which may serve as protective factors for children with multiple disabilities [3]. One study found that students with multiple disabilities demonstrated positive ratings of self-concept and self-perceptions though they persistently performed poorly on measures of achievement, which indicate that this population may demonstrate "an overestimation of their capabilities and an underestimation of the task" [4].

As previously indicated, the needs and relationships of students with disabilities are complex, and the complexity of needs is exacerbated when a child has multiple disabilities. Fortunately, research has indicated that students with multiple disabilities have previously reported feeling cared about by others and experiencing difficulty with school to a degree that is similar to their typically developing peers [5]. Educators must find ways to highlight their students' abilities and provide opportunities for these students to enhance their self-perceptions; this may serve to increase the likelihood that these students will experience success in their adult lives, particularly in the context of transition programs. For example, a case study 
revealed that mastery of simple household tasks can have profound, lasting effects on the life of a child with multiple disabilities [6]. By completing chores at home, an individual with comorbid Spina Bifida and intellectual disabilities increased his self-determination and improved his relationship with his father.

Beyond increasing children's self-perceptions, there are additional factors to consider when assessing potential educational outcomes for individuals with multiple disabilities. Jansen, van der Putten, and Vlaskamp [7] investigated parents' feelings about the support their children - many of whom suffered from profound intellectual and multiple disabilities - received outside the home. Although most parents reported satisfaction with the services provided to their child by school personnel or through related programs, the authors noted that certain areas of support were lacking. First, the researchers discovered a trend wherein parents' positive feelings for the level of support their children received decreased as the child aged, which may indicate the need for an increased focus on the services received by older students. Next, the poorest satisfaction among parents for the category of coordinated and comprehensive care for both the child and the family, which may indicates a need for service providers to facilitate and increase collaboration with parents to ensure positive outcomes for this population.

Recent findings indicate that the children of parents who are active participants in their child's special educational programming are increasingly served in general education settings with supports [8], which indicates that parental involvement positively impacts services and opportunities to for this population to be served with their typically developing peers. The authors noted that "social and emotional growth is also facilitated by time spent with non-disabled students whose abilities and maturation are wide-ranging" [8].

To receive special education services, school-based teams must evaluate students with disabilities to determine their educational need for specially designed instruction. This process involves determining which disability category best fits the student in question. Although "labeling" a student appears intuitive and logical, the process is may be hindered due to a "one size fits all" mentality. Researchers have found that the provision of supports and services provided to students vary by label, as well supports and services among students with the same label [9]. In a study involving interviews with 22 students, families, and educators, researchers found that students most commonly used person-first language (i.e., "a student with a disability") rather than disability-first (i.e, "a disabled student"), while parents were equally divided on their use of person-first and disability-first language, and teachers primarily used disability-first language [10]. This indicates that educators may view their students based on the supports and services they provide to them, while students may view their peers as similar to them, which may internally support their identity development.

Regarding school-age disability service delivery, students are serviced and protected (and local educational agencies are governed) by the Individuals with Disabilities Education Act of 2004 (IDEA). Upon transitioning out of secondary education, the Americans with Disabilities Act of 1990 (ADA) orders the selfidentification from students [11,12]. The shift in responsibility and accountability from school-based teams for school-age services to individuals with disabilities into adulthood may be a deterring factor for students with disabilities in attending postsecondary institutions, despite the legal protections of individuals with disabilities provided through the Section 504 of the Rehabilitation Act of 1973. Barnard-Brak and colleagues [12] endeavored to identify if negative attitudes towards requesting services in postsecondary institutions would decrease with the provision of one-on-one interventions for students, and found that interventions with an educational component decreased students' negative attitudes and increased the number of students who attempted postsecondary educational programming. Thus, providing interventions for students with disabilities who are transitioning, especially for those with multiple disabilities, prepares students for the independent, daily living skills that are necessary independently manage their provision of services and supports into adulthood.

Federal law mandates that students with disabilities are to be provided with transition services, which are identified and supported through a students' individual education program (IEPs) that attempt to prepare them for and transition into post-secondary education and adulthood [13]. Transition services are required to be provided to students by age 16 in most states, but many schools are attempting to do so by age 14 , which is shown to result in higher rates of employment for this population. Because of the severity of and complex nature of needs that students with multiple disabilities possess, early transition programs may prompt promising outcomes for their social and vocational success. To predict how likely a student will succeed within a transition program, certain factors may be analyzed. Oftentimes, one's level of inclusion within general education curriculum and setting, one's amount of career or technical education training and credentials, and one's involvement in work-study programs are highly correlated with post-secondary educational outcomes for students with disabilities [14]. High degrees of general education inclusion and career or technical training are related to positive transition outcomes, whereas one's involvement in work-

Predictors of Educational Outcomes of Students with Multiple Disabilities: Results ... (Karen H. Larwin) 
study programs are negatively related to successful transition. Additionally, student outcomes are enhanced when teachers provide instruction using transition planning curricula [15].

In addition to supports provided in the contexts of the home and the school, longitudinal research regarding transition programs for individuals with multiple disabilities has suggested the need for support within the community setting for these students to succeed [16]. In order to prepare graduating seniors for the work force, Project SEARCH was developed. Job retention rates and employment outcomes were higher for those employed through SEARCH-partnered businesses than businesses that were not part of the program, which indicates that community support is essential to the educational and vocational success of individuals with multiple disabilities who participate in transition programs [16];[17];[18]. However, other researchers have found that while supported employment programs for individuals with developmental disabilities, Project SEARCH participation, which is tailored directly to the unique needs of this population, resulted in higher compensation and retention rates in the workforce [19]. The aforementioned literature illustrates the importance of positive relationships and foundational work and life skills that are necessary to prepare individuals with multiple disabilities for transition programs. It is essential to address these factors across all settings: home, school, and community, as well as enlist local businesses and community agencies and organizations to support positive outcomes for students with multiple disabilities. The present study research attempts to investigate the following components as predictors of students' educational outcomes: the relationships of students with multiple disabilities, the effectiveness of home and school practices, and the feelings of those directly involved with these factors. It is hypothesized that there will be a correlation between the amount of time students with multiple disabilities spend talking about school with their parents and their desire to attend college. Next, it is hypothesized that a perceived caring parent relationship will result in students having a stronger desire to attend college. Finally, it is hypothesized that the children of parents with higher levels of education will more likely to want to attend post-secondary programming.

\section{RESEARCH METHOD}

The data used for this research was gathered from the unrestricted AdHealth Survey data. The total sample consisted of 460 respondents $(n=460)$, which consisted of both parents and students. For the purpose of the present study, only participants who identified themselves as having multiple disabilities were selected; this resulted in 11 participants $(n=11)$. To provide a comparison group, a stratified random sample of 33 participants $(n=33)$ was selected. Bias within the sample was reduced through the use of stratified random sampling, which also provided a representative sample. All data were dealt with equally without deference to any specific group.

Two variables were collapsed into factors, the first of which involved how often the students discussed school-related issues with their parent(s). The second factor was created by collapsing multiple variables was concerned with the quality of the relationship between the parent(s) and the child. Table 1 indicates each of the individual variables included in the first collapsed factor, termed School Discussion.

Table 1. Collapsed Variable School Discussion

\begin{tabular}{l}
\hline \multicolumn{1}{c}{ School Discussion } \\
\hline S16Q17H RES MOM-TALKED SCH-GRADES-W1 \\
S16Q17I RES MOM-WORKED SCH-PROJECT-W1 \\
S16Q17J RES MOM-TALKED SCH-OTHER-W1 \\
S16Q18H RES DAD-TALKED SCH-GRADES-W1 \\
S16Q18I RES DAD-WORKED SCH-PROJECT-W1 \\
S16Q18J RES DAD-TALKED SCH-OTHER-W1 \\
\hline
\end{tabular}

The School Discussion factor created by taking the sum of the responses across the item listed in Table 1. Table 2 indicates each of the individual variables included in the second collapsed factor, termed Parent Relationship.

Table 2. Collapsed Variable Parent Relationship

\begin{tabular}{l}
\hline \multicolumn{1}{c}{ Parent Relationship } \\
\hline S18Q1 MOM-WARM AND LOVING-W1 \\
S18Q4 MOM-GOOD COMMUNICATION-W1 \\
S18Q5 MOM-GOOD RELATIONSHIP-W1 \\
S18Q23 DAD-WARM AND LOVING-W1 \\
S18Q24 DAD-GOOD COMMUNICATION-W1 \\
S18Q25 DAD-GOOD RELATIONSHIP-W1 \\
\hline
\end{tabular}

IJERE Vol. 7, No. 3, September 2018 : 176-181 
The Parent Relationship factor was collapsed, and the variables shown in Table 2 were averaged to create this factor. The data used in the current investigation is from a national study therefore the findings are considered to be reliable and representative of the larger population.

\section{RESULTS AND ANALYSIS}

As shown in Figure 1, the largest percentage of parents reported being high-school graduates at 34.1 percent. Participant responses to Want to Attend College and Likely to Attend College were are examined. These items ask respondents to indicate their response on a one to five scale, with one being the lowest level of endorsement, and five being the highest level of endorsement. Figure 1 visually depicts the percentages of self-reported level of parent education.

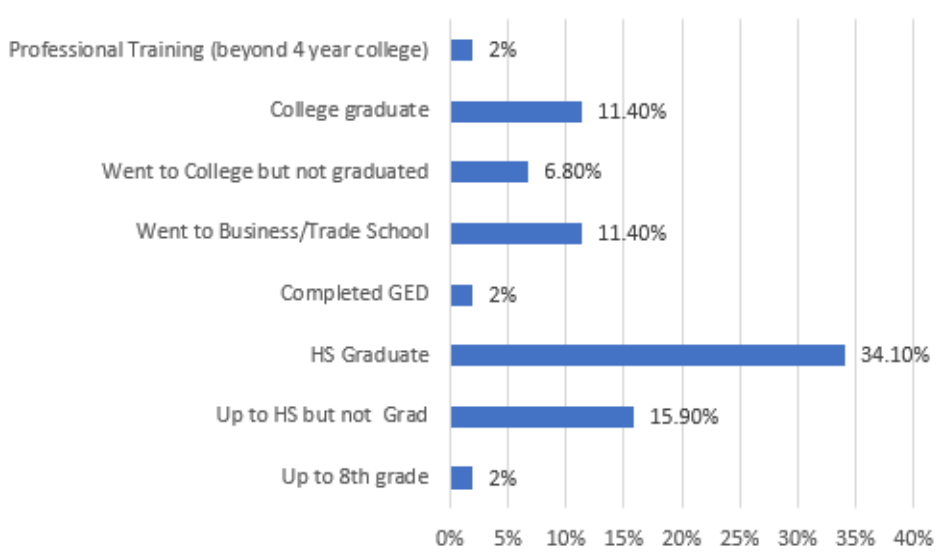

Figure 1. Reported level of parent education

Table 3. examines the descriptive statistics for the variables of Parent Relationship, School Discussion, Want to Attend College, and Likely Will Attend College.

Table 3. Descriptive Statistics

\begin{tabular}{lll}
\hline Variable & Mean & SD \\
\hline Parent Relationship & 1.89 & .74 \\
School Discussion & 1.90 & 1.52 \\
Want to Attend College & 4.23 & 1.33 \\
Likely Will Attend College & 4.09 & 1.25 \\
\hline
\end{tabular}

Evaluation of skewness and kurtosis indicates that all levels were within acceptable ranges for all variables (|2.0 and |5.0|, respectively). Zero-order correlations were conducted across all of the variables. The only significant result was between the variables titled, "Want to Attend College" and "Likely Will Attend College," $r=0.68, p<0.01$. Next, a chi-square test was conducted to determine if there was a difference in the levels of responding to the variables of "Want to Attend College" and "Likely Will Attend College" for students with and without multiple disabilities. The statistical analysis revealed no significant difference between respondents on the "Likely Will Attend College" variable, $\chi^{2}(4)=6.71, p=0.15$. However, the researchers discovered significant differences among participants with multiple disabilities as compared to the comparison group on the "Want to Attend College" variable, $\chi^{2}(5)=21.65, p<0.01$. Students identified as having multiple disabilities endorsed both questions more positively relative to their non-disabled peers. 


\section{DISCUSSION}

The current investigation hypothesized that greater amounts of school discussion between parents and children with multiple disabilities would result in increased desire to attend college. However, statistical analyses revealed no significant relationships between these variables. Next, it was hypothesized that a perceived caring parent relationship would also result in a stronger desire to attend college. Similarly, statistical analyses revealed no significant relationships between these variables. Finally, it was hypothesized that higher parental levels of education would result in a desire to attend college. Based upon the results of the statistical analyses, it was necessary to reject all three of the researchers' original hypotheses. Overall, the sole significant finding was discovered using the chi-square test in the differences existed between the group with multiple disabilities and the comparison group on the "Want to Attend College". The results indicate that the students identified with disabilities endorsed their interest in going to college higher than the students from the general student population. Additionally, students with disabilities also endorsed "Likely Will Attend College" higher than their general student population peers. These finding are important since students with disabilities are less likely to attend post-secondary education opportunities [19].

Results of the present study are inconsistent with findings reported in previous studies. Findings suggest no significant correlations between quality of relationships with parents, reported parent level of education, quality of discussion about school between children with multiple disabilities and their parents [8];[5];[16]. A large research study examining programs to support students with disabilities in their successful transition to college found that mentor programs are key to student success [20]. As such, much more research in this area is needed.

There are several limitations in the present study. First, the low incidence (or occurrence) of children having multiple disabilities in the general population is limited. Moreover, many questions that were studied went unanswered by members of the sample, resulting in missing data for some questions. Next, the database from which the data were obtained is based on self-report surveys, which contain the potential of being unreliable. A final limitation is the variance of severity of disability inherently present within the category of multiple disabilities. For instance, some respondents reported two disability-related limitations while others reported six limitations.

In the future, if a relationship between the aforementioned variables is found, as shown in previous research, it would be beneficial to extend the questions to the outcomes of transition services for students with multiple disabilities. Providing respondents with additional options for questions may reveal useful information. For example, rather than strictly measuring one's desire to attend college, it may be useful to explore student outcomes pertaining to post-secondary job attainment and retention. Lastly, an additional line of inquiry may explore parental attitudes about their child's disability status and its impact on postsecondary outcomes.

\section{CONCLUSION}

The current investigation focuses on the transition of students from high school, and whether students with multiple disabilities have a different mindset regarding post-secondary opportunities. While students with disabilities expressed more interest in wanting to go to college, all other results were not found to be significantly different across the groups of students (those with disabilities, and those without). Although this finding did not align with the hypothesized outcome, these results suggest that all students have the same range of opinions regarding going onward for a post-secondary education and goal setting regarding their post-secondary aspirations.

These findings a significant considering the general outcomes for students with disabilities that are cited above. While students with disabilities may have a more challenging time attending a traditional brick and mortar institution, the exponential growth of online and distance education options can make this transition to a variety of post-secondary options more available. And, while the access to higher education grows for all populations of students, career-technology schools, colleges, and universities must ensure that they are appropriately equipped to provide these special students with added supports that will be needed.

\section{REFERENCES}

[1] Roper, S. O., Allred, D. W., Mandleco, B., Freeborn, D., \& Dyches, T. (2014). Caregiver burden and sibling relationships in families raising children with disabilities and typically developing children. Families, Systems \& Health, 32, 241-246.

[2] Serdity, C., \& Burgman, I. (2012). Being the older sibling: Self-perceptions of children with disabilities. Children \& Society, 26, 37-50.

IJERE Vol. 7, No. 3, September 2018: 176-181 
[3] Nijs, S., Vlaskamp, C., \& Maes, B. (2016). Children with PIMD in interaction with peers with PIMD or siblings. Journal of Intellectual Disability Research, 60, 28-42.

[4] Varsami, P., \& Agaliotis, I. (2011). Profiles of self-concept, goal-orientation, and self-regulation in students with physical, intellectual, and multiple disabilities: Implications for instructional support. Research in Developmental Disabilities, 32, 1548-1555.

[5] Bebich, A. C., Oliver, T. D., Limperos, A. M., Schade, B. P., \& Larwin, K. H. (2016). Perceptions of students with multiple disabilities and typically developing peers. European Journal of Special Education Research, 1(3), 1-11.

[6] Harr, N., Dunn, L., \& Price, P. (2011). Case study on effect of household task participation on home, community, and work opportunities for a youth with multiple disabilities. Work, 39(4), 445-453. doi: 10.3233/WOR-2011-1194

[7] Jansen, S. L. G., van der Putten, A. A. J., \& Vlaskamp, C. (2012). What parents find important in the support of a child with profound intellectual and multiple disabilities. Child: Care, Health, and Development, 39(3), 432-441. doi: 10.1111/j.1365-2214.2012.01381.x

[8] Banerjee, R., Sundeed, T., Hutchinson, S. R., \& Jackson, L. (2017). Factors that explain placement decisions for students with multiple disabilities: Findings from national data. Journal of Research in Special Educational Needs, 17(2), 110-122.

[9] Borders, C., Meinzen-Derr, J., Wiley, S., Bauer, A. \& Embury, D. C. (2015). Students who are deaf with additional disabilities: Does education label impact language services? Deafness \& Education International, 17(4), 204-218. doi: 10.1179/1557069X15Y.0000000006

[10] Back, L. T., Keys, C. B., McMahon, S. D., \& O’Neill, K. (2016). How we label students with disabilities: A framework of language use in an urban school district in the United States. Disability Studies Quarterly, 36(4), 1-1.

[11] Stodden, R. A., Whelley, T., Chang, C., \& Harding, T. (2001). Current status of educational support provision to students with disabilities in postsecondary education. Journal of Vocational Rehabilitation, 16, 189-198.

[12] Barnard-Brak, L., Schmidt, M., Wei, T., Hodges, T., and Robinson, E. L. (2013). Providing postsecondary transition services to youth with disabilities: Results of a pilot program. Journal of Postsecondary Education and Disability, 26(2), 135-144.

[13] Cimera, R. E., Burgess, S., and Bedesem, P. L. (2014). Does providing transition services by age 14 produce better vocational outcomes for students with intellectual disability? Research and Practice for Persons with Severe Disabilities, 39 (1), 47-54.

[14] Baer, R., Daviso, III, A. W., Flexer, R. W., McMahan Queen, R., \& Meindl, R.S. (2011). Students with intellectual disabilities: Predictors of transition outcomes. Career Development for Exceptional Individuals, 34(3), 132-141. doi: $10.1177 / 0885728811399090$

[15] Lee, Y., Wehmeyer, M. L, Palmer, S. B., Williams-Diehm, K., Davies, D. K., \& Stock, S. E. (2012). Examining individual and instruction-related predictors of the self-determination of students with disabilities: Multiple regression analyses. Remedial and Special Education, 33(3), 150-161.

[16] Christensen, J., Hetherington, S., Daston, M., \& Riehle, E. (2014). Longitudinal outcomes of project SEARCH in upstate New York. Journal of Vocational Rehabilitation, 42, 247-255. doi: 10.3233/JVR-150746

[17] Müller, E., \& VanGilder, R. (2014). The relationship between participation in project SEARCH and job readiness and employment for young adults with disabilities. Journal of Vocational Rehabilitation, 40, 15-26.

[18] Persch, A. C., Cleary, D. S., Rutkowski, S., Malone, H. I., Darragh, A. R., \& Case-Smith, J. D. (2015). Current practices in job matching: A project SEARCH perspective on transition. Journal of Vocational Rehabilitation, 43, 259-273.

[19] Erickson, M.J., \& Larwin, K.H. (2016). The potential impact of online/distance education for students with disabilities in higher education: Results from a meta-analytic investigation and existing research. The International Journal of Evaluation and Research in Education, 5(1), 76-81.

[19] Schall, C. M., Wehman, P., Brooke, V., Graham, C., McDonough, J., Brooke, A., Allen, J. (2015). Employment interventions for individuals with ASD: The relative efficacy of supported employment with or without prior project SEARCH training. Journal of Autism \& Developmental Disorders, 45, 3990-4001.

[20] Lindsay, S., Hartman, L., Fellin, M. (2016). A systematic review of mentorship programs to facilitate transition to post-secondary education and employment for youth and young adults with disabilities. Disability and Rehabilitation, 38(14), 1329-1349. 